\title{
Titanium Dioxide Nanotubes as Model Systems for Electrosorption Studies
}

\author{
Xian Li ${ }^{1}$, Samantha Pustulka ${ }^{2}$, Scott Pedu ${ }^{2}$, Thomas Close ${ }^{2}$, Yuan Xue ${ }^{3}$, Christiaan Richter ${ }^{2,4}$ (i) \\ and Patricia Taboada-Serrano ${ }^{1,2, * \text { (iD }}$ \\ 1 Microsystems Engineering Ph.D. Program, Rochester Institute of Technology, \\ Rochester, NY 14623-5603, USA; x19206@rit.edu \\ 2 Department of Chemical Engineering, Rochester Institute of Technology, Rochester, NY 14623-5603, USA; \\ spustulka3@gatech.edu (S.Pu.); spedu@andrew.cmu.edu (S.Pe.); tclose@mit.edu (T.C.); cpr@hi.is (C.R.) \\ 3 Materials Science Program, University of Rochester, Rochester, NY 14627-0216, USA; yxue4@ur.rochester.edu \\ 4 Industrial Engineering, Mechanical Engineering and Computer Science, School of Engineering \\ and Natural Sciences, University of Iceland, Reykjavik 600169-2039, Iceland \\ * Correspondence: ptsche@rit.edu; Tel.: +1-585-475-7337
}

Received: 2 April 2018; Accepted: 23 May 2018; Published: 5 June 2018

\begin{abstract}
Highly ordered titanium dioxide nanotubes $\left(\mathrm{TiO}_{2} \mathrm{NTs}\right)$ were fabricated through anodization and tested for their applicability as model electrodes in electrosorption studies. The crystalline structure of the $\mathrm{TiO}_{2}$ NTs was changed without modifying the nanostructure of the surface. Electrosorption capacity, charging rate, and electrochemical active surface area of $\mathrm{TiO}_{2}$ NTs with two different crystalline structures, anatase and amorphous, were investigated via chronoamperometry, cyclic voltammetry, and electrochemical impedance spectroscopy. The highest electrosorption capacities and charging rates were obtained for the anatase $\mathrm{TiO}_{2} \mathrm{NTs}$, largely because anatase $\mathrm{TiO}_{2}$ has a reported higher electrical conductivity and a crystalline structure that can potentially accommodate small ions within. Both electrosorption capacity and charging rate for the ions studied in this work follow the order of $\mathrm{Cs}^{+}>\mathrm{Na}^{+}>\mathrm{Li}^{+}$, regardless of the crystalline structure of the $\mathrm{TiO}_{2}$ NTs. This order reflects the increasing size of the hydrated ion radii of these monovalent ions. Additionally, larger effective electrochemical active surface areas are required for larger ions and lower conductivities. These findings point towards the fact that smaller hydrated-ions experience less steric hindrance and a larger comparative electrostatic force, enabling them to be more effectively electrosorbed.
\end{abstract}

Keywords: electrosorption; titania nanotubes; nanostructured electrodes

\section{Introduction}

The properties of charged interfaces and the electrosorption of ions on charged surfaces have a remarkable influence on the kinetics of various electrochemical processes, including those having technological importance such as water desalination and energy storage [1-4]. Electrosorption is a process where ions of opposite charge (counter-ions) are immobilized within a region known as the electrical double layer (EDL), which forms in the vicinity of the electrolyte-electrode interface when a low direct current potential is applied $[5,6]$. Electrosorption takes place during electrochemical reactions, charging/discharging of batteries, operation of electrochemical capacitors (ECs) and capacitive deionization (CDI) [7,8]. Recently, CDI technology, which relies on the reversible removal of ions from the solution by trapping them within the EDL, has gathered great interest due to its low energy cost, environmental friendliness, and no secondary pollution $[9,10]$. Electrochemical capacitors (ECs) use the electric field in the EDLs established at the electrode-electrolyte interface to 
store electrical energy. Without Faradaic (redox) reaction at EC electrodes, the EDL energy storage mechanism makes fast energy uptake and delivery, and good power performance possible [11,12]. Therefore, the properties of the EDL crucially determine the ions that can be removed from aqueous solutions in CDI and the energy that can be stored in ECs. Finally, the characteristics of the EDL directly influence the outcome of electrochemical reactions by adding another "resistance" or providing more "housing" for electrostatic charge storage to the processes.

Previous literature on electrosorption mainly focused on electrode development, and was mostly for specific applications [13-15]. Porous carbons are often the choice of materials for electrosorption as they combine a high surface area and good electrical conductivity $[16,17]$. In spite of considerable efforts directed towards increasing surface area of carbon-based electrode materials in the last decades, CDI and ECs performance are still not at the required level in order to become competitive technologies. One of the factors contributing to this is the inaccessibility of the surface area and the disordered pore arrangements of carbon materials that result in only part of the total surface area being utilized during electrosorption. Additionally, it was found that electrosorption capacity is dependent on the type of ion and its characteristics, e.g., hydrated ion radius, charge and even specific interactions with the surface. These dependencies cannot be fully captured by the classical theory usually employed to model CDI and EC performance. Chen et al. noted that during CDI operation with activated carbon electrodes at the same concentration, smaller ions depicted size-affinity by being preferentially captured by EDLs [18]. Furthermore, they claimed that in a mixed $\mathrm{Cl}^{-}$and $\mathrm{NO}_{3}{ }^{-}$solution, $\mathrm{Cl}^{-}$is preferably electrosorped over $\mathrm{NO}_{3}{ }^{-}$. This interesting observation suggests that specific interactions between the ion and electrode indeed played a role in the electrosorption process since the $\mathrm{Cl}^{-}$and $\mathrm{NO}_{3}{ }^{-}$ have a similar hydrated radius (3.31 $\AA$ and $3.35 \AA$ respectively), same concentration, and identical ionic charge in the test [18]. However, the current knowledge of this interaction is still rudimentary, and many experimental observations remain difficult to interpret because the property of carbon-based electrodes such as the architecture, composition, and pore size are difficult to control in order to perform a systematic study of these phenomena.

A model electrode with tunable properties is required in order to better understand the effects of electrode properties and their interactions with different ions on electrosorption. Electrodes with defined and tunable architectures, where pore sizes and pore lengths can be well defined, would allow for systematic investigation of the effects of confinement and surface properties on the electrosorption of ions with specific characteristics [19,20]. Owing to well-defined pore diameters and lengths via anodization of titanium foil in specifically formulated chemical baths; highly ordered and self-organized titanium dioxide nanotubes $\left(\mathrm{TiO}_{2} \mathrm{NT}\right)$ are a very appealing candidate for fulfilling this role $[19,20]$. A particular advantage of $\mathrm{TiO}_{2} \mathrm{NT}$ is that the crystalline structure is easily tuned by simply annealing between $350-450{ }^{\circ} \mathrm{C}$ in air (from amorphous to anatase), without modifying the electrode architecture. Anatase $\mathrm{TiO}_{2} \mathrm{NT}$ is a good approach to compensate for the low conductivity of amorphous $\mathrm{TiO}_{2} \mathrm{NT}$, while offering a potentially different ion-accommodation mechanism. Anatase $\mathrm{TiO}_{2}$ contains a cavity in its crystalline structure where a small ion could insert itself [21]. In the present work, $\mathrm{TiO}_{2}$ NTs were fabricated and tested for their suitability as model electrodes for electrosorption studies. Electrosorption of three monovalent alkaline cations $\left(\mathrm{Li}^{+}, \mathrm{Na}^{+}, \mathrm{Cs}^{+}\right)$was systematically explored in order to capture the interactive effects of the crystalline structure and hydrated ion radius on electrosorption capacity, charge dynamics and utilization of electrode surface area. The three ions chosen for the present work bear the same charge, but have distinctly different hydrated radiuses, which allowed us to investigate the effects of ion size during electrosorption. Additionally, the three ions selected are relevant in terms of their applications: desalination, energy storage and deionization of radioactive waste. The goal of the study was to demonstrate the suitability of anodized $\mathrm{TiO}_{2} \mathrm{NT}$ electrodes to study how electrode properties and ion characteristics affect electrosorption. 


\section{Materials and Methods}

\subsection{Fabrication of Titanium Dioxide Nanotube Electrodes}

Titanium dioxide nanotube electrodes $\left(\mathrm{TiO}_{2} \mathrm{NT}\right)$ were fabricated following the method described in previous work [21,22]. Pieces of titanium foil (purity 99.7\%, from STREM Chemicals Inc., Newburyport, MA, USA) were cut to the desired electrode size and rinsed with ethanol. A $150 \mathrm{~mL}$ solution of Ethylene Glycol and aqueous $0.05 \mathrm{~mol} / \mathrm{L}$ ammonium fluoride with a volume ratio of 50:1 was introduced into a temperature-controlled anodization cell under dry air in order to synthesize electrodes at different anodization conditions. The foil was anodized at varying temperatures for $1 \mathrm{~h}$ in this solution with a platinum counter electrode at fixed voltages of $60 \mathrm{~V}$. Temperature was one of the anodization parameters explored in order to define the electrode-surface architecture. Highly-ordered and uniform cylindrical tubes were the desired electrode architecture for the electrosorption studies. After anodization, the electrodes were removed from the solution, rinsed with methanol, and allowed to air-dry. Four electrode samples were prepared simultaneously in order to ensure consistent characteristics. Some of the samples were annealed in air at $425^{\circ} \mathrm{C}$ for $1 \mathrm{~h}$ in order to change the $\mathrm{TiO}_{2}$ crystalline structure from amorphous to anatase - this structure has a higher reported electrical conductivity [19]. The mass of the NTs was determined prior and after annealing by weighing, in order to detect any change in mass that might have occurred during annealing. Scanning electron microscopy (SEM, Zeiss Auriga CrossBeam SEM) was used to characterize the morphology of $\mathrm{TiO}_{2}-\mathrm{NT}^{-}$ electrodes. The specific surface area was determined via statistical analysis of the dimensions of the nanotubes measured from SEM images taken at random locations on the electrodes synthesized for this work, in the same fashion as previous work [22]. The mass of the nanotubes was determined via direct weighing.

\subsection{Electrochemical Tests}

All electrochemical tests in this work were performed using a BASi Cell stand C3 potentiostat (Bioanalytical Systems BASi, West Lafayette, IN, USA), the counter electrode was a BASi MW-1032 platinum electrode, and the reference electrode was BASi Ag/ AgCl (BASi MW-2052). The working electrodes were the $\mathrm{TiO}_{2} \mathrm{NT}$ prepared as detailed above. Electrochemical tests were performed with three monovalent alkaline metal ions $\left(\mathrm{Li}^{+}, \mathrm{Na}^{+}, \mathrm{Cs}^{+}\right)$as counter-ions and the same co-ion $\left(\mathrm{Cl}^{-}\right)$in $20 \mathrm{~mL}$ of each of the following 0.1 M solutions: Sodium Chloride ( $\mathrm{NaCl})$, Lithium Chloride ( $\mathrm{LiCl})$, and Cesium Chloride $(\mathrm{CsCl})$. The area of the working electrode was $2 \mathrm{~cm}^{2}$, corresponding to a mass of electrode $\left(\mathrm{TiO}_{2}\right.$ nanotubes and titanium foil) equal to $0.010 \pm 0.001 \mathrm{~g}$ in all cases. The $\mathrm{Ag} / \mathrm{AgCl}$ reference electrode and the platinum-wire counter electrode were placed in the solution along with the working electrode in a typical three-electrode setup. The volume and concentration of the solutions were selected to ensure that ions were not depleted from the bulk solution at higher applied potentials. This was to avoid ion-concentration effects on electrosorption capacity. A blanking procedure was run before each electrochemical test, comprising a constant potential of $+600 \mathrm{mV}$ vs. Ag/ AgCl being held for $5 \mathrm{~min}$. This was done to ensure that each test had the same initial conditions. The potentiostat was programmed for each electrochemical test with the specifications described below.

One chronoamperometry cycle (CA) included $2 \mathrm{~s}$ of quiet time with no applied potential $(0 \mathrm{mV})$, $130 \mathrm{~s}$ at a constant negative applied potential (charge) and $130 \mathrm{~s}$ at the same constant positive applied potential (discharge). The pairs of negative and positive applied potentials during charge and discharge were $-200 \mathrm{mV} /+200 \mathrm{mV}$; $-400 \mathrm{mV} /+400 \mathrm{mV}$; and $-600 \mathrm{mV} /+600 \mathrm{mV}$. Each CA cycle (quiet time, charge, and discharge) was repeated at least fifteen times with a blanking procedure between each cycle in order to target true equilibrium electrosorption capacity with the measurements.

In the electrochemical impedance spectroscopy (EIS) test, the three-electrode cell was set up in the same way as for the CA and CV tests. The EIS tests were conducted with a Gamry Reference 600 (Gamry Instruments, Warminster, PA, USA) with the amplitude of the sinusoidal AC voltage signal of 
$5 \mathrm{mV}$ over the frequency range $1 \mathrm{mHz}$ to $1 \mathrm{kHz}$. Electrochemical impedance spectroscopy (EIS) spectra were analyzed with the Z-view software.

\subsection{Electrosorption Capacity}

Electrosorption capacity was calculated assuming that each electron unit of charge was neutralized by one ionic charge. The accumulated charge was calculated via numerical integration of the area underneath the current response curve with time during the charging cycle. Values for electrosorption capacity were double-checked via calculation of the charge released during the discharge part of the cycle.

\section{Results}

\subsection{Surface Architecture of Anodized $\mathrm{TiO}_{2}$ Electrodes}

Figure 1a,b shows SEM images (top and side view) of one of the annealed $\mathrm{TiO}_{2} \mathrm{NT}$ electrodes anodized with a potential of $60 \mathrm{~V}$ for $1 \mathrm{~h}$ at $15{ }^{\circ} \mathrm{C}$. Regular nanotube structure with uniform diameters and lengths were obtained at these anodization conditions, which were subsequently used in electrosorption experiments. Furthermore, the as-prepared $\mathrm{TiO}_{2} \mathrm{NT}$ (non-annealed, amorphous) electrode is morphologically identical with the $\mathrm{TiO}_{2} \mathrm{NT}$ after annealing at $425{ }^{\circ} \mathrm{C}$ for $1 \mathrm{~h}$ in air. Statistical analysis of SEM images was used in order to determine the mean diameter and length for the $\mathrm{TiO}_{2}-\mathrm{NT}$ electrodes prepared. Based on the measurement from the SEM images, it can be seen that the $\mathrm{TiO}_{2}$ NT electrode has a diameter of $41.4 \pm 4 \mathrm{~nm}$, length of $2136 \pm 50 \mathrm{~nm}$ and specific surface area of $31.4 \pm 2.2 \mathrm{~m}^{2} / \mathrm{g}$. This level of control is highly desirable for electrosorption studies. However, it is also necessary to point out that surface architecture is highly sensitive to the anodization conditions. For instance, in Figure 1c, when anodization was carried out with the same anodization-bath formulation, applied potential and anodization time but at $5{ }^{\circ} \mathrm{C}$, nano needle structures, instead of nanotubes, were obtained. This suggests that the low temperature may have changed the balance between the competitive oxidation reaction and oxide dissolution reaction taking place during Ti anodization in the presence of $\mathrm{F}^{-}$. Another example is provided in Figure $1 \mathrm{~d}$, in which the anodization conditions were the same, but the temperature was $35^{\circ} \mathrm{C}$. One can observe that the nanotube structure is less regular and defined than the one depicted in Figure 1a. This is because the high temperature accelerates both the fluoride etching and oxide layer growth, resulting in the cluster-like nanotube bulk appearance and deconstruction of some nanotubes.
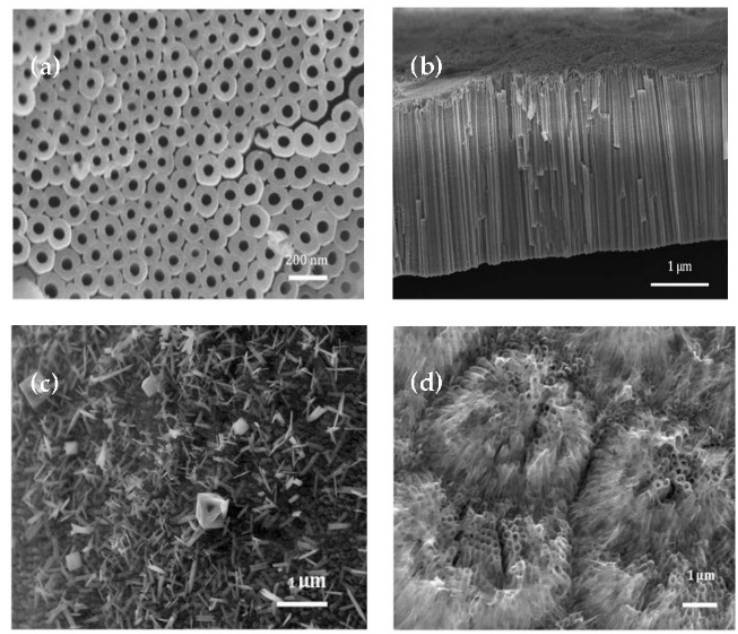

Figure 1. SEM images of $\mathrm{TiO}_{2} \mathrm{NT}$ electrodes (a), top view of $\mathrm{TiO}_{2} \mathrm{NT}$ anodized at $60 \mathrm{~V} 15^{\circ} \mathrm{C}$, annealed; (b) side view of $\mathrm{TiO}_{2} \mathrm{NT}$ anodized at $60 \mathrm{~V} 15^{\circ} \mathrm{C}$, annealed; (c) top view of $\mathrm{TiO}_{2} \mathrm{NT}$ anodized at $60 \mathrm{~V}$ $5{ }^{\circ} \mathrm{C}$, non-annealed; (d) top view of $\mathrm{TiO}_{2} \mathrm{NT}$ anodized at $60 \mathrm{~V} 35^{\circ} \mathrm{C}$, non-annealed). 
Electrodes of uniform $\mathrm{TiO}_{2} \mathrm{NTs}$ were prepared at applied potentials equal to $60 \mathrm{~V}$, a temperature of $15^{\circ} \mathrm{C}$, and an anodizaion time of $1 \mathrm{~h}$ for subsequent electrosorption studies, in order to demonstrate their applicability as model electrodes. Half of the electrodes were annealed in order to modify their crystalline structure without modifying their architecture. The annealed electrodes are identified as $\mathrm{TiO}_{2}-\mathrm{NT}-\mathrm{A}$, and the non-annealed electrodes are identified as $\mathrm{TiO}_{2}-\mathrm{NT}-\mathrm{NA}$ hereafter.

\subsection{Effects of Electrode Crystalline Structure and Ionic Strength on Electrosorption}

The effect of the $\mathrm{TiO}_{2}$ NTs characteristic on electrosorption capacity was investigated in terms of its crystalline structure. As stated earlier, two groups of $\mathrm{TiO}_{2} \mathrm{NTs}$ : amorphous (non-annealed, $\mathrm{TiO}_{2}$ NT-NA) and anatase (annealed, $\mathrm{TiO}_{2}$ NT-A) were selected in order to study the effect of the $\mathrm{TiO}_{2}$ crystalline structure on electrosorption capacity of similarly-charged ions. Anatase $\mathrm{TiO}_{2} \mathrm{NT}$ electrodes are prepared via annealing the as-synthesized amorphous electrodes in air at $350{ }^{\circ} \mathrm{C}$ for $1 \mathrm{~h}$. The surface structure ( $\mathrm{TiO}_{2}$ NT diameter and length) of amorphous and anatase electrodes is identical, as it is not modified during annealing. Tighineanu et al. reported that the conductivity of anatase $\mathrm{TiO}_{2}$ can be higher than that of amorphous $\mathrm{TiO}_{2}$ by several orders of magnitude [19]. Due to high conductivity, it was expected that the $\mathrm{TiO}_{2}$ NT-A would lead to high charge densities at the surface of the electrodes, i.e., larger electrosorption capacities. Figure 2a,b depicts electrosorption capacity for $\mathrm{Cs}^{+}, \mathrm{Na}^{+}$and $\mathrm{Li}^{+}$for both $\mathrm{TiO}_{2}$ NT-NA and $\mathrm{TiO}_{2}$ NT-A electrodes. In Figure $2 \mathrm{a}, \mathrm{TiO}_{2}$ NT-A electrode shows higher electrosorption capacity for each ion than that of the $\mathrm{TiO}_{2} \mathrm{NT}-\mathrm{NA}$ electrode, as expected. It is also shown that for $\mathrm{TiO}_{2} \mathrm{NT}-\mathrm{A}$, the highest electrosorption capacity, $29.78 \mu \mathrm{mol} / \mathrm{m}^{2}$, was achieved during $\mathrm{Cs}^{+}$electrosorption at $-600 \mathrm{mV}$. As for $\mathrm{TiO}_{2} \mathrm{NT}-\mathrm{NA}$, the highest electrosorption capacity was obtained for $\mathrm{Cs}^{+}$at $-600 \mathrm{mV}$ with a value equal to $12.19 \mu \mathrm{mol} / \mathrm{m}^{2}$. This is only $40.9 \%$ of the highest electrosorption capacity of $\mathrm{Cs}^{+}$on $\mathrm{TiO}_{2}$ NT-A at the same applied potential. Regardless of ion, the $\mathrm{TiO}_{2}$ NT-A electrode substantially exhibited better electrosorption performance, which can be attributed to the higher conductivity of $\mathrm{TiO}_{2}-\mathrm{NT}-\mathrm{A}$. Additionally, $\mathrm{TiO}_{2}-\mathrm{NT}-\mathrm{A}$ possesses a tunnel structure of anatase that may potentially aid electron transport and ion accommodation. It should be pointed out that, at a specific applied potential, the electrosorption capacity for various ions with both $\mathrm{TiO}_{2} \mathrm{NT}-\mathrm{A}$ and $\mathrm{TiO}_{2}$ NT-NA electrodes follows the order of $\mathrm{Li}^{+}<\mathrm{Na}^{+}<\mathrm{Cs}^{+}$. For example, as seen in Figure 2b, with an applied potential of $-600 \mathrm{mV}$, electrosorption capacities of $\mathrm{Li}^{+}, \mathrm{Na}^{+}$, and $\mathrm{Cs}^{+}$with $\mathrm{TiO}_{2} \mathrm{NT}-\mathrm{A}$ were 17.88, 24.79, and $29.77 \mu \mathrm{mol} / \mathrm{m}^{2}$, respectively, while with $\mathrm{TiO}_{2} \mathrm{NT}-\mathrm{NA}$, the electrosorption capacities were $6.82,8.91$, and $12.19 \mu \mathrm{mol} / \mathrm{m}^{2}$ for $\mathrm{Li}^{+}, \mathrm{Na}^{+}$, and $\mathrm{Cs}^{+}$, respectively. This trend can be explained by the fact that smaller hydrated ions experience less steric hindrance towards packing within the EDL and may also experience stronger electrostatic forces. In fact, the trend in electrosorption capacity aligns with the decreasing size of the hydration radii for $\mathrm{Li}^{+}, \mathrm{Na}^{+}$, and $\mathrm{Cs}^{+}$(which are equal to $3.82 \AA$, $3.58 \AA$, and $3.29 \AA$, respectively) [20]. Furthermore, the comparative advantage of smaller hydrated ions towards electrosorption is more marked with $\mathrm{TiO}_{2}$ NT-A electrodes. For instance, at $-200 \mathrm{mV}$, the elecrosorption capacity of $\mathrm{Cs}^{+}$with $\mathrm{TiO}_{2}$ NT-NA was 2.9 times higher than that the corresponding value to $\mathrm{Li}^{+}$, whereas this value was equal to 6.1 in the case of $\mathrm{TiO}_{2} \mathrm{NT}-\mathrm{A}$. The differences in electrosorption behavior did not limit themselves to capacity at equilibrium, but also in the dynamic behavior of the charging process (i.e., accumulation of charge within the EDL). 


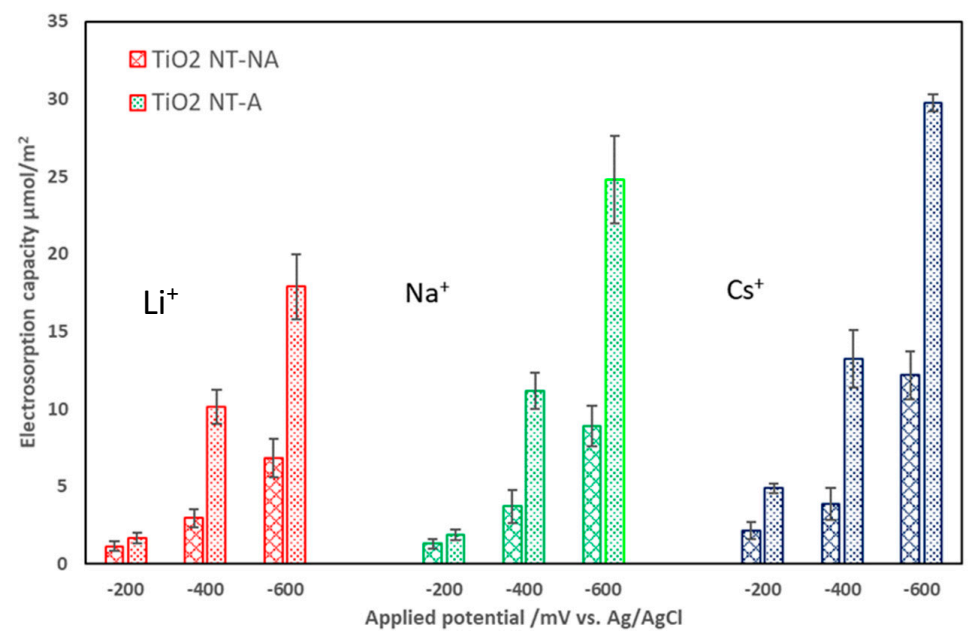

(a)

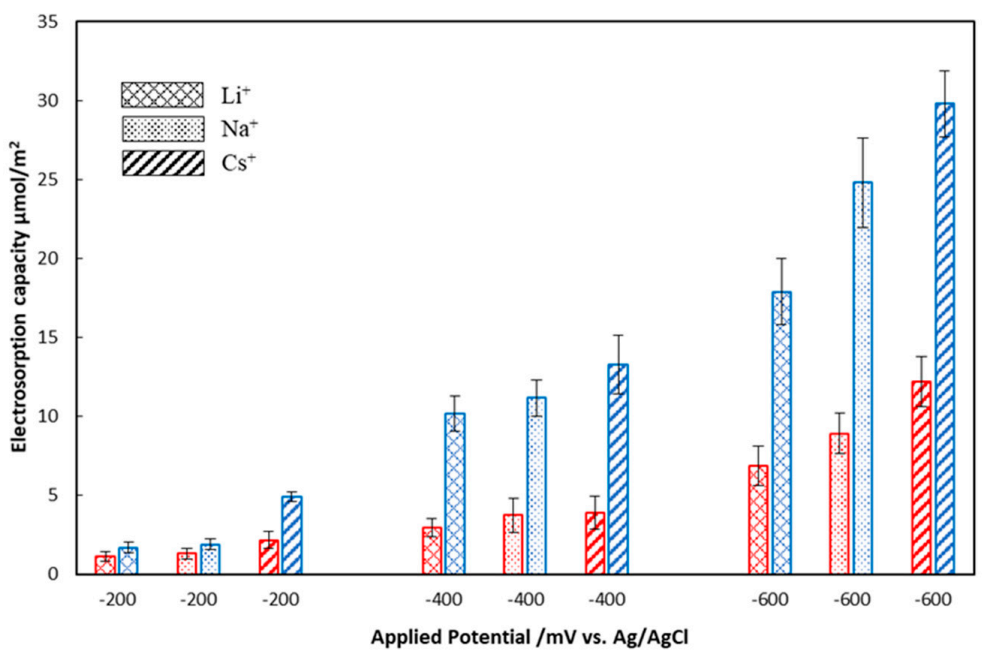

(b)

Figure 2. Electrosorption capacity of $\mathrm{Li}^{+}, \mathrm{Na}^{+}$, and $\mathrm{Cs}^{+}$(a) at various applied potentials; and (b) for different electrodes (red bars for $\mathrm{TiO}_{2}$ NT-NA and blue bars for $\mathrm{TiO}_{2}$ NT-A).

\subsection{Charging Dynamics Dependence on Ion and Crystalline Structure}

Figure $3 \mathrm{a}-\mathrm{c}$ shows the dynamic behavior of EDL formation for $\mathrm{TiO}_{2}$ NT-A and $\mathrm{TiO}_{2}$ NT-NA under $-200 \mathrm{mV},-400 \mathrm{mV}$, and $-600 \mathrm{mV}$, respectively. When the applied potential was $-200 \mathrm{mV}$, the highest charging rate was obtained with the $\mathrm{TiO}_{2} \mathrm{NT}-\mathrm{A}$ electrode and $\mathrm{Cs}^{+}$in Figure $3 \mathrm{a}$. Furthermore, it is evident that the charging rates for $\mathrm{TiO}_{2}$ NT-A were consistently higher than the rates obtained for $\mathrm{TiO}_{2}$ NT-NA with all the ions studied in this work. Increasing applied potential does not only increase the charging rate, but also accentuates the difference between charging rates of anatase and amorphous $\mathrm{TiO}_{2} \mathrm{NT}$ electrodes. When the applied potential increased to $-400 \mathrm{mV}$, it became more apparent of the advantage of $\mathrm{TiO}_{2}$ NT-A in terms of charging rate. From Figure 3b, two groups of charging curves are clearly identifiable resulting from the differences in the electrode crystalline structure. Figure $3 \mathrm{c}$ depicts even more dispersed behavior of the curves of charging rate, with a clear advantage for $\mathrm{TiO}_{2}$ NT-A. One should notice that the charging rate is consistent with the decreasing hydrated ion radii. As seen in Figure $3 a-c$, the charging rate followed the order of $\mathrm{Cs}^{+}>\mathrm{Na}^{+}>\mathrm{Li}^{+}$with both $\mathrm{TiO}_{2} \mathrm{NT}-\mathrm{A}$ and $\mathrm{TiO}_{2}$ NT-NA. Interestingly, the dispersion among charging curves brought about by the differences in hydrated ion radii become more marked as applied potential increased. 

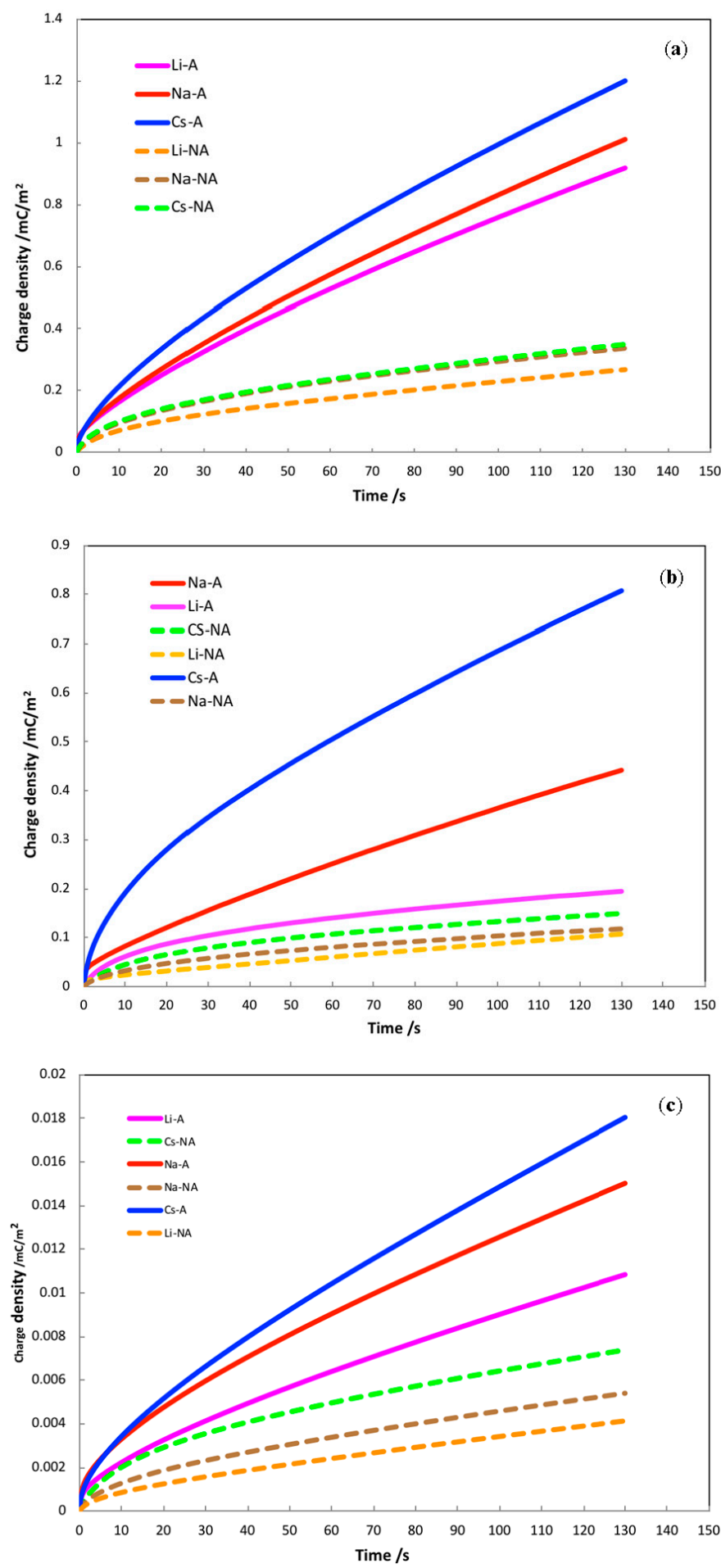

Figure 3. Charging rate of $\mathrm{Li}^{+}, \mathrm{Na}^{+}$, and $\mathrm{Cs}^{+}$with $\mathrm{TiO}_{2}-\mathrm{NT}-\mathrm{A}$ and $\mathrm{TiO}_{2}-\mathrm{NT}-\mathrm{NA}$ under $(\mathbf{a})-600 \mathrm{mV}$ vs . $\mathrm{Ag} / \mathrm{AgCl}$; (b) $-400 \mathrm{mV}$ vs. $\mathrm{Ag} / \mathrm{AgCl}$; and (c) $-200 \mathrm{mV}$ vs. $\mathrm{Ag} / \mathrm{AgCl}$ (solid line for $\mathrm{TiO}_{2}-\mathrm{NT}-\mathrm{A}$ and dashed line for $\mathrm{TiO}_{2}$-NT-NA).

Summarizing, (i) $\mathrm{TiO}_{2}$ NT-A electrodes exhibited faster charging rates for each ion at every specific potential than that of the $\mathrm{TiO}_{2}$ NT-NA electrode due to the high conductivity of anatase; (ii) $\mathrm{Cs}^{+}$with $\mathrm{TiO}_{2}$ NT-A consistently exhibited the highest charging rates at each tested potential, followed by $\mathrm{Na}^{+}$ and $\mathrm{Li}^{+}$. This last finding confirms the fact that smaller hydrated ions have the advantage of less steric hindrance and most likely stronger electrostatic interactions during electrosorption. 


\subsection{Electrochemically Active Surface Area}

It is not difficult to conclude that ion electrosorption benefits from the large surface area of $\mathrm{TiO}_{2}$ NTs. The $\mathrm{TiO}_{2}$ NT-A and $\mathrm{TiO}_{2}$ NT-NA electrodes did not have any morphological difference, i.e., the surface structures on both electrodes were identical. Given the higher electrosorption capacity and charging rates exhibited by $\mathrm{TiO}_{2}$ NT-A, it was necessary to determine how much of the total surface area of $\mathrm{TiO}_{2}$ NTs was effectively used during electrosorption. Furthermore, it was necessary to explore how the $\mathrm{TiO}_{2} \mathrm{NTs}$ crystalline structure and any possible electrode-ion interactions may have influenced the effective area involved in electrosorption. Electrochemical active surface area (EASA) for each case was estimated based on cyclic voltammetry (CV) and electrochemical impedance spectroscopy (EIS) measurements [23-25]. In order to obtain EDL capacitance via CV, a series of CV tests at multiple scan rates were carried out. The current in the non-Faradaic potential region, measured via $C V$, which is assumed to be generated due to double-layer charging exclusively, is equal to the product of the scan rate, $v$, and the double-layer capacitance, $C_{D L}$, as given in Equation $(1)[25,26]$.

$$
\mathrm{i}_{\mathrm{DL}}=\mathrm{vC}_{\mathrm{DL}}
$$

Examples of $\mathrm{CVs}$ of the $\mathrm{TiO}_{2}$ NT-NA and $\mathrm{TiO}_{2}-\mathrm{A}$ are depicted in Figure $4 \mathrm{a}, \mathrm{b}$. The CV tests were carried out in a non-Faradaic potential region at the following scan rates: 6, 12, 25, 50, and $100 \mathrm{mV} / \mathrm{s}$. After acquiring the charging current at $-0.3 \mathrm{~V}$ vs. $\mathrm{Ag} / \mathrm{AgCl}$, the cathodic and anodic charging currents were plotted as a function of scan rate $\mathrm{v}$, which yields a straight line with a slope equal to $C_{D L}$, as depicted in Figure $4 \mathrm{c}, \mathrm{d}$. The determined electrochemical double-layer capacitance of the system, $C_{D L}$, is the average of the absolute value of the slope of the straight lines regressed from the experimental data.
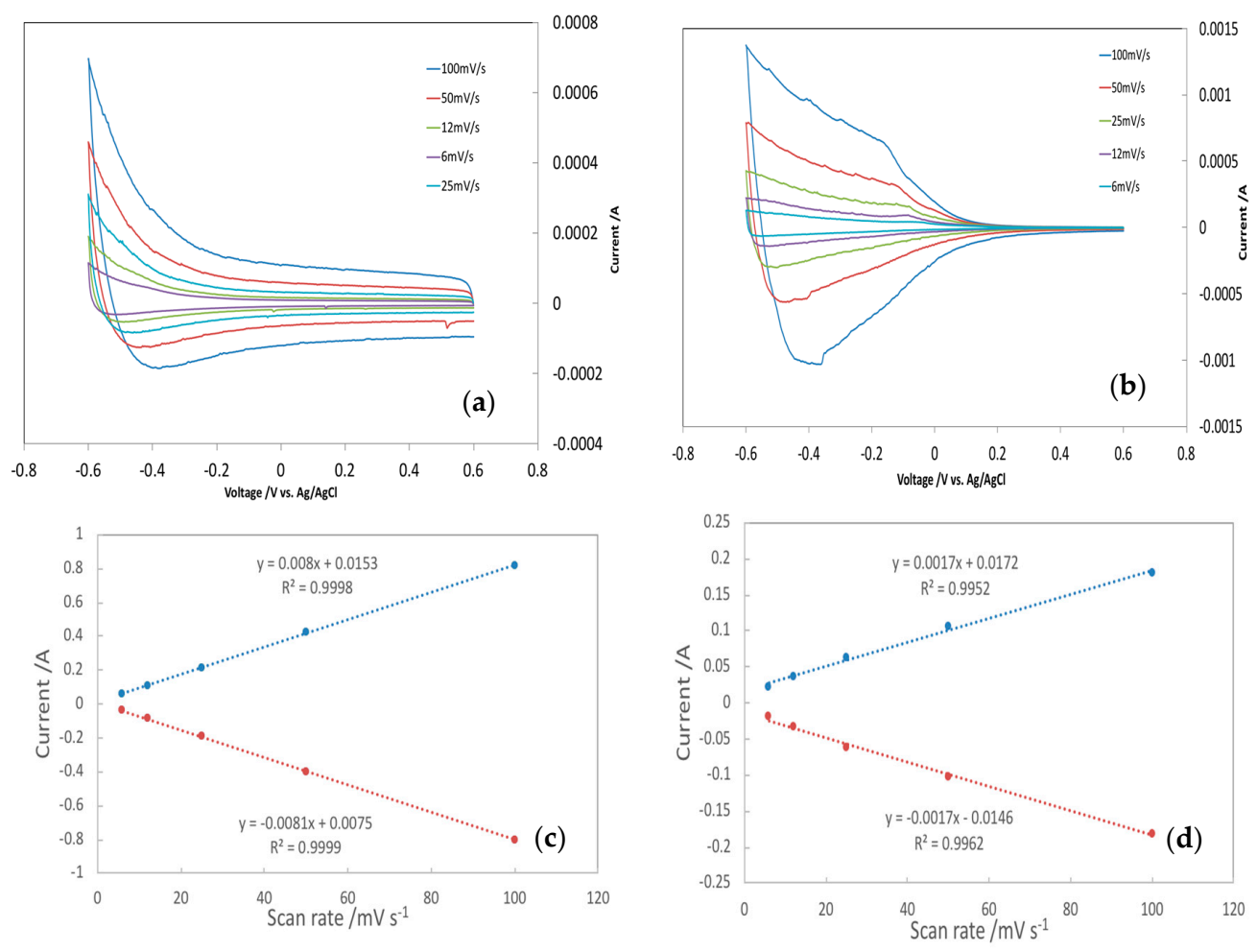

Figure 4. Cyclic voltammograms $1 \mathrm{M} \mathrm{NaCl}$ at various scan rates for (a) $\mathrm{TiO}_{2} \mathrm{NT}-\mathrm{NA}$; (b) $\mathrm{TiO}_{2} \mathrm{NT}-\mathrm{A}$; and EDL capacitance calculations for the determination of EASA (c) $\mathrm{TiO}_{2}$ NT-NA; (d) $\mathrm{TiO}_{2} \mathrm{NT}-\mathrm{A}$. For the determination of EDL capacitance, charging currents measured at $-0.3 \mathrm{~V}$ vs. $\mathrm{Ag} / \mathrm{AgCl}$, plotted as a function of the scan rate from Figure $4 \mathrm{a}, \mathrm{d}$, cathodic and anodic charging currents measured at $-0.3 \mathrm{~V}$ vs. $\mathrm{Ag} / \mathrm{AgCl}$, plotted as a function of scan rate. 
Upon having the double-layer capacitance, $\mathrm{C}_{\mathrm{DL}}$, the EASA of the sample was calculated according to Equation (2):

$$
\mathrm{EASA}=\frac{\mathrm{C}_{\mathrm{DL}}}{\mathrm{C}_{\mathrm{s}} \cdot \mathrm{m}}
$$

where $\mathrm{m}$ is the mass of $\mathrm{TiO}_{2} \mathrm{NT}, \mathrm{C}_{\mathrm{s}}$ is the specific capacitance of the sample and was calculated according to Equation (3):

$$
\mathrm{C}_{\mathrm{s}}=\frac{\mathrm{C}}{\mathrm{A}}=\frac{\mathrm{Q}}{\mathrm{E} \times \mathrm{A}} \text {, where } \mathrm{Q}=\int_{0}^{\mathrm{t}} \mathrm{idt}
$$

where $i$ is the time-dependent current response in the CA test, $t$ is the time of charge/discharge in the $\mathrm{CA}$ test, $\mathrm{E}$ is the applied potential in the $\mathrm{CA}$ test, $\mathrm{Q}$ is the total transferred charge in the CA test, and $\mathrm{A}$ is the area of the electrode.

The double-layer capacitance was independently determined via electrochemical impedance spectroscopy (EIS). Figure 5a,b shows the Nyquist plots of different ions for $\mathrm{TiO}_{2} \mathrm{NT}$ amorphous (NA) and anatase (A), respectively. The Nyquist plots are interpreted with the help of an equivalent circuit, shown in the inset of Figure 5, in which the electrochemical system is approximated by the modified Randles circuit. The intersection of the impedance spectra with the real axis at the high frequency region end is the bulk resistance $\left(R_{\mathrm{S}}\right)$ including all contact resistance and resistance attributed to the electrolyte. The high frequency arc corresponds to the charge transfer limiting process and is ascribed to the charge transfer resistance $\left(\mathrm{R}_{\mathrm{ct}}\right)$ at the contact interface between the electrode and electrolyte solution in parallel with a constant phase element $(\mathrm{CPE})$ related to the double-layer capacitance. The frequency-dependent impedance of the CPE is given by Equation $(4)[27,28]$ :

$$
\mathrm{Z}_{\mathrm{CPE}}=\frac{1}{\mathrm{Q}_{0} \cdot(\mathrm{i} \omega)^{\alpha}}
$$

where $\mathrm{Q}_{0}$ is a constant with dimensions $\mathrm{F} \mathrm{s}^{-(1-\alpha)}, \omega$ is the frequency of the sinusoidal applied potential, $\mathrm{i}=(-1)^{1 / 2}$, and $\alpha$ is a dimensionless parameter, related to the phase angle of the frequency response, which has a value between 0 and $1[27,28]$. Based on the circuit model used here, the double-layer capacitance was calculated according to Equation (5) [27,28]:

$$
\mathrm{C}_{\mathrm{DL}}=\mathrm{Q}^{\frac{1}{\alpha}} \cdot\left[\left(\frac{1}{\mathrm{R}_{\mathrm{S}}}+\frac{1}{\mathrm{R}_{\mathrm{ct}}}\right)\right]^{\left(1-\frac{1}{\alpha}\right)}
$$

Note that when $\alpha=1$, the CPE behaves as a pure capacitor and $C_{D L}=Q$, and when $\alpha=0$, the $C P E$ behaves as a pure resistor and $C_{D L}$ is not detectable $[25,26]$. For example, from the EIS measurement of the $\mathrm{Li}^{+}$with the annealed $\mathrm{TiO}_{2} \mathrm{NT}$ electrode at an applied potential of $-0.05 \mathrm{~V}$ vs. $\mathrm{Ag} / \mathrm{AgCl}$ shown in Figure $5, R_{s}=24.4 \Omega, R_{c t}=10.3 \Omega, Q=0.148 \mathrm{mF} \mathrm{s}^{-(1-\alpha)}$, and $\alpha=0.605$. The calculated $C_{D L}$ from Equation (5) is $0.012 \mathrm{~F}$. The calculated $R_{\mathrm{ct}}$ for all experimental conditions are listed in Table 1.

Table 1. Electrochemically-active surface area (EASA) for $\mathrm{TiO}_{2}$ NT-A and $\mathrm{TiO}_{2}$ NT-NA determined via $\mathrm{CV}$ and EIS.

\begin{tabular}{ccccccc}
\hline Electrode & Target Ion & $\mathbf{R}_{\mathrm{ct}} / \mathbf{\Omega}$ & EASA-CV/m $/ \mathbf{g}$ & EASA-EIS/m $/ \mathbf{g}$ & $\begin{array}{c}\text { EASA-CV/Specific } \\
\text { Area/\% }\end{array}$ & $\begin{array}{c}\text { EASA-EIS/Specific } \\
\text { Area/\% }\end{array}$ \\
\hline $\mathrm{TiO}_{2}$ NT-A & $\mathrm{Li}^{+}$ & 10.3 & 14.1 & 13.7 & 44.7 & 43.6 \\
$\mathrm{TiO}_{2}$ NT-NA & $\mathrm{Li}^{+}$ & 13.9 & 21.1 & 20.6 & 67.1 & 65.7 \\
$\mathrm{TiO}_{2}$ NT-A & $\mathrm{Na}^{+}$ & 7.6 & 12.3 & 11.7 & 39.3 & 37.7 \\
$\mathrm{TiO}_{2}$ NT-NA & $\mathrm{Na}^{+}$ & 9.9 & 17.8 & 16.8 & 56.8 & 57.7 \\
$\mathrm{TiO}_{2}$ NT-A & $\mathrm{Cs}^{+}$ & 3.1 & 8.9 & 9.2 & 27.6 & 29.7 \\
$\mathrm{TiO}_{2}$ NT-NA & $\mathrm{Cs}^{+}$ & 6.2 & 16.2 & 15.9 & 51.5 & 50.4 \\
\hline
\end{tabular}




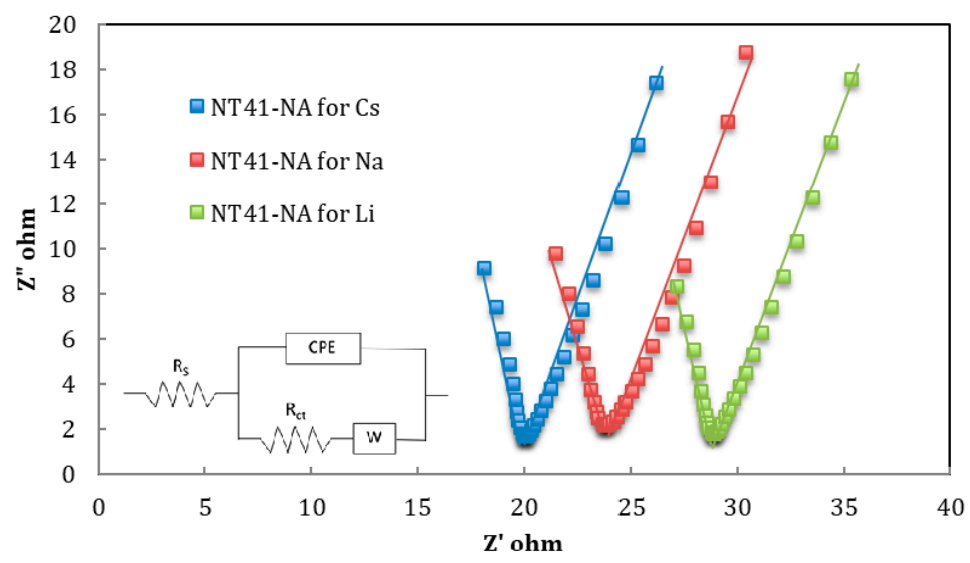

(a)

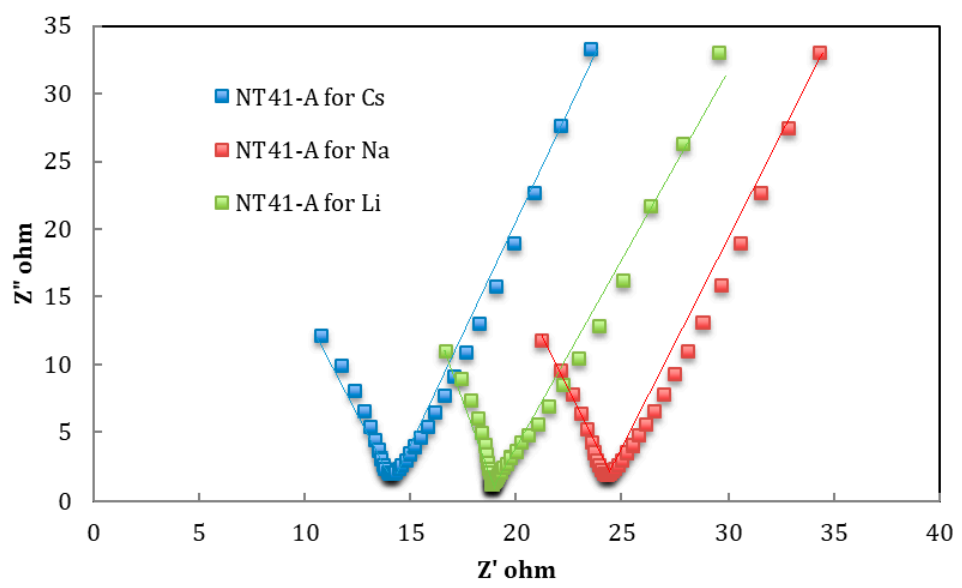

(b)

Figure 5. Nyquist plots for (a) $\mathrm{TiO}_{2}$ NT-NA and (b) $\mathrm{TiO}_{2}$ NT-A. The solid lines are the modeling fits to the EIS data by using the simplified Randles circuit shown in the inset of Figure $5 \mathrm{a}$.

For a particular ion, the $\mathrm{TiO}_{2}$ NT-A results in a lower charge transfer resistance $\left(\mathrm{R}_{\mathrm{ct}}\right)$ than that of $\mathrm{TiO}_{2}$ NT-NA, as expected, due to the higher electrical conductivity of the anatase phase. Two components are expected to contribute to the charge transfer resistance in electrosorption. The first one is due to the process of ion diffusion from the bulk electrolyte to the electrode surface. The second contributing factor is due to entrapment of ions within the EDL. The experimental conditions chosen for this work ensured that the ion concentration in the bulk electrolyte is much higher than the equilibrium concentration of electrosorption so that the resistance due to diffusion can be, in principle, neglected. Therefore, the charge transfer resistance can be equated to the resistance that an ion at the surface of an electrode has to overcome in order to be immobilized within the EDL. The $\mathrm{R}_{\mathrm{ct}}$ of different ions for both electrodes, $\mathrm{TiO}_{2}$ NT-A and $\mathrm{TiO}_{2}$ NT-NA, followed the trend of $\mathrm{Li}^{+}>\mathrm{Na}^{+}>\mathrm{Cs}^{+}$, which is the reversed order of the hydrated ion radius as seen in Table 1 . This finding confirmed our previous conclusion that the smaller hydrated ion radii presented lower steric resistance and possibly stronger electrostatic interactions. In general, the EDL capacitance measured by EIS is within $10 \%$ of that measured by the scan-rate dependent CVs, and the EASA obtained for a given sample by the two methodologies tend to agree within $\pm 10 \%$. Values of EASA were also correlated to hydrated-ion radius, but with a reverse trend: the largest ion $\mathrm{Li}^{+}$exhibits the largest EASA, followed by $\mathrm{Na}^{+}$and then $\mathrm{Cs}^{+}$. It seems that packing of larger ions within the EDL requires more surface area. The EASA of $21.1 \mathrm{~m}^{2} / \mathrm{g}$, which is found in the $\mathrm{Li}^{+}$electrosorption test with $\mathrm{TiO}_{2} \mathrm{NT}-\mathrm{NA}$, is the largest value reaching $67.1 \%$ of the total surface area, while the smallest EASA of $8.9 \mathrm{~m}^{2} / \mathrm{g}, 27.6 \%$ of the total surface area, is found in the $\mathrm{Cs}^{+}$electrosorption test with $\mathrm{TiO}_{2}$ NT-A. 
Summarizing, anodized $\mathrm{TiO}_{2} \mathrm{NT}$ electrodes of controlled surface structures proved to be a very effective model-electrode system in order to study experimentally ion-size effects and ion-electrode interaction effects during electrosorption.

\section{Discussion}

The crystalline structure of the $\mathrm{TiO}_{2}-\mathrm{NT}$ electrode was a determinant factor of electrosorption capacity and charging rate for all ions studied in this work. Due to the high conductivity, the electrosorption capacity of the anatase $\mathrm{TiO}_{2}-\mathrm{NT}$ electrode outperformed that of the amorphous $\mathrm{TiO}_{2}-\mathrm{NT}$ electrode for all three targeted ions, $\mathrm{Li}^{+}, \mathrm{Na}^{+}$, and $\mathrm{Cs}^{+}$and tested potentials, $-200 \mathrm{mV}$, $-400 \mathrm{mV}$, and $-600 \mathrm{mV}$. Additionally, the high conductivity of the anatase form of the $\mathrm{TiO}_{2}-\mathrm{NTs}^{-}$ is favorable for fast EDL formation. As the surface architecture for all electrodes is identical, the only difference between the annealed and non-annealed electrodes was in the crystalline structure. This mainly affects the electrical conductivity. However, a tunnel structure in the annealed (anatase) electrodes is not present in the non-annealed electrodes. This tunnel structure could potentially play a role as well.

The electrosorption tests evidenced that the hydrated ion radius plays a critical role during electrosorption. The electrosorption and charging rate of both anatase and amorphous $\mathrm{TiO}_{2}-\mathrm{NT}^{-}$ electrodes follow the same trend of $\mathrm{Li}^{+}<\mathrm{Na}^{+}<\mathrm{Cs}^{+}$, which agrees with the order of decreasing hydrated ion radius $\mathrm{Li}^{+}(3.82 \AA)<\mathrm{Na}^{+}(3.58 \AA)<\mathrm{Cs}^{+}(3.29 \AA)$. The small ion can take advantage of low steric hindrance and higher relative electrostatic forces in order to be immobilized within the EDL more efficiently. This behavior becomes more marked with increasing applied potential. In fact, the lower charge transfer resistance is achieved by the combination of the anatase $\mathrm{TiO}_{2}$ electrode and the ion with the smaller hydrated radius.

Higher electrical conductivity translates into higher effective potentials at the solid-liquid interface of the electrodes, i.e., larger driving forces during EDL charging and formation. They also translate into larger surface charge densities to be neutralized via EDL, i.e., higher electrosorption capacities. If EDL charging and structure only responded to ionic strength (ion concentration and ionic charge), as predicted by Classical EDL Theory, no differences should have been detected for ions bearing the same charge at the same concentrations. This work confirms predictions of molecular modelling that EDL structure is determined by competitive energy and steric effects [29-32]. This fact can also be visualized via the determination of EASA through independent electrochemical techniques.

The EASA based on cyclic voltammetry (CV) and EIS agree with each other very well. The amorphous $\mathrm{TiO}_{2}-\mathrm{NA}$ electrode exhibited higher EASA than that of anatase $\mathrm{TiO}_{2}-\mathrm{NT}$, which is contrary to the electrosorption capacity for any particular ion at the same potential. It is noted that the amorphous $\mathrm{TiO}_{2}-\mathrm{NT}$ utilized more surface area but reached a lower electrosorption capacity. The EASA of anatase $\mathrm{TiO}_{2}-\mathrm{NT}$ decreased with the ion hydrated radius, which indicated that smaller hydrated ions are more easily packed within the EDL, confirming the observations gained by measuring electrosorption capacity and charging rate. Furthermore, the lower EASA in the case of $\mathrm{TiO}_{2}-\mathrm{NT}-\mathrm{A}$ confirms the fact that these electrodes present lower surface charge densities due to their lower electrical conductivity. The order of increasing EASA with increasing hydrated ion size $\left(\mathrm{Cs}^{+}>\mathrm{Na}^{+}>\mathrm{Li}^{+}\right)$further confirms the occurrence of steric hindrance in the structure of the EDL.

\section{Conclusions}

A series of highly-ordered $\mathrm{TiO}_{2}$ nanotubes $\left(\mathrm{TiO}_{2}-\mathrm{NT}\right)$ with two different crystalline structures, amorphous and anatase, were synthesized by anodization, and were used as model-system electrodes in the study of ion size and crystalline structure effects during electrosorption of alkaline metal ions. The electrodes of controlled geometry allowed for the systematic investigation of ion size and crystalline effects on electrosorption capacity, charging dynamics, and electrochemical active surface area (EASA), via well-known electrochemistry techniques. The simple geometry of the electrodes allowed for the clear identification of steric effects on the behavior of EDL formation and structure 
that had been predicted via molecular simulations, but had not been unequivocally determined via experimentation. The highly tunable, regular nanotube structure of the electrodes proposed in this work, made the elucidation of steric effects during electrosorption and EDL formation possible.

Author Contributions: Conceptualization, P.T.-S. and X.L.; Methodology, P.T.-S., X.L. and C.R.; Validation, X.L., S.Pu., S.Pe., T.C. and Y.X.; Formal Analysis, X.L.; Investigation, X.L., S.Pu., S.Pe., T.C. and Y.X.; Resources, P.T.-S.; Data Curation, X.L., S.Pu., S.Pe., T.C. and P.T.-S.; Writing-Original Draft Preparation, X.L.; Writing-Review \& Editing, X.L. and P.T.-S.; Visualization, X.L. and P.T.-S.; Supervision, P.T.-S.; Project Administration, P.T.-S.; Funding Acquisition, P.T.-S.

Funding: This research received no external funding.

Acknowledgments: To the Kate Gleason Fund.

Conflicts of Interest: The authors declare no conflict of interest.

\section{References}

1. Zhang, C.; He, D.; Ma, J.; Tang, W.; Waite, T.D. Faradaic reactions in capacitive deionization (CDI)-problems and possibilities: A review. Water Res. 2018, 128, 314-330. [CrossRef] [PubMed]

2. Khan, Z.U.; Yan, T.; Shi, L.; Zhang, D. Improved Capacitive Deionization by Using 3D Intercalated Graphene Sheet-Sphere Nanocomposite Architectures. Environ. Sci. Nano 2018, 5, 980-991. [CrossRef]

3. Yu, X.; Ma, H.; Du, W.; Qu, L.; Li, C.; Shi, G. Robust graphene composite films for multifunctional electrochemical capacitors with an ultrawide range of areal mass loading toward high-rate frequency response and ultrahigh specific capacitance. Energy Environ. Sci. 2018, 11, 559-565.

4. Wang, Z.; Tan, Y.; Yang, Y.; Zhao, X.; Liu, Y.; Niu, L.; Tichnell, B.; Kong, L.; Kang, L.; Liu, Z. Pomelo peels-derived porous activated carbon microsheets dual-doped with nitrogen and phosphorus for high performance electrochemical capacitors. J. Power Sources 2018, 378, 499-510. [CrossRef]

5. Foo, K.; Hameed, B. A short review of activated carbon assisted electrosorption process: An overview, current stage and future prospects. J. Hazard. Mater. 2009, 170, 552-559. [CrossRef] [PubMed]

6. Beden, B.; Morin, M.-C.; Hahn, F.; Lamy, C. "In situ" analysis by infrared reflectance spectroscopy of the adsorbed species resulting from the electrosorption of ethanol on platinum in acid medium. J. Electroanal. Chem. Interfacial Electrochem. 1987, 229, 353-366. [CrossRef]

7. Sun, Y.; Zeng, W.; Sun, H.; Luo, S.; Chen, D.; Chan, V.; Liao, K. Inorganic/polymer-graphene hybrid gel as versatile electrochemical platform for electrochemical capacitor and biosensor. Carbon 2018, 132, 589-597. [CrossRef]

8. Liu, P.; Yan, T.; Shi, L.; Park, H.S.; Chen, X.; Zhao, Z.; Zhang, D. Graphene-based materials for capacitive deionization. J. Mater. Chem. A 2017, 5, 13907-13943. [CrossRef]

9. Suss, M.; Porada, S.; Sun, X.; Biesheuvel, P.; Yoon, J.; Presser, V. Water desalination via capacitive deionization: What is it and what can we expect from it? Energy Environ. Sci. 2015, 8, 2296-2319. [CrossRef]

10. Liu, Y.; Nie, C.; Liu, X.; Xu, X.; Sun, Z.; Pan, L. Review on carbon-based composite materials for capacitive deionization. RSC Adv. 2015, 5, 15205-15225. [CrossRef]

11. Fic, K.; He, M.; Berg, E.J.; Novák, P.; Frackowiak, E. Comparative operando study of degradation mechanisms in carbon-based electrochemical capacitors with $\mathrm{Li}_{2} \mathrm{SO}_{4}$ and $\mathrm{LiNO}_{3}$ electrolytes. Carbon 2017, 120, 281-293. [CrossRef]

12. Przygocki, P.; Abbas, Q.; Béguin, F. Capacitance enhancement of hybrid electrochemical capacitor with asymmetric carbon electrodes configuration in neutral aqueous electrolyte. Electrochim. Acta 2018, 296, 640-648. [CrossRef]

13. Rasines, G.; Lavela, P.; Macías, C.; Zafra, M.C.; Tirado, J.L.; Parra, J.B.; Ania, C.O. N-doped monolithic carbon aerogel electrodes with optimized features for the electrosorption of ions. Carbon 2015, 83, 262-274. [CrossRef]

14. Rasines, G.; Lavela, P.; Macías, C.; Zafra, M.; Tirado, J.; Ania, C. On the use of carbon black loaded nitrogen-doped carbon aerogel for the electrosorption of sodium chloride from saline water. Electrochim. Acta 2015, 170, 154-163. [CrossRef] 
15. Li, K.; Guo, D.; Lin, F.; Wei, Y.; Liu, W.; Kong, Y. Electrosorption of copper ions by poly (m-phenylenediamine)/reduced graphene oxide synthesized via a one-step in situ redox strategy. Electrochim. Acta 2015, 166, 47-53. [CrossRef]

16. Kalluri, R.; Biener, M.; Suss, M.; Merrill, M.; Stadermann, M.; Santiago, J.; Baumann, T.; Biener, J.; Striolo, A. Unraveling the potential and pore-size dependent capacitance of slit-shaped graphitic carbon pores in aqueous electrolytes. Phys. Chem. Chem. Phys. 2013, 15, 2309-2320. [CrossRef] [PubMed]

17. Tsouris, C.; Mayes, R.; Kiggans, J.; Sharma, K.; Yiacoumi, S.; DePaoli, D.; Dai, S. Mesoporous carbon for capacitive deionization of saline water. Environ. Sci. Technol. 2011, 45, 10243-10249. [CrossRef] [PubMed]

18. Chen, Z.; Zhang, H.; Wu, C.; Wang, Y.; Li, W. A study of electrosorption selectivity of anions by activated carbon electrodes in capacitive deionization. Desalination 2015, 369, 46-50. [CrossRef]

19. Tighineanu, A.; Ruff, T.; Albu, S.; Hahn, R.; Schmuki, P. Conductivity of $\mathrm{TiO}_{2}$ nanotubes: Influence of annealing time and temperature. Chem. Phys. Lett. 2010, 494, 260-263. [CrossRef]

20. Nightingale Jr, E. Phenomenological theory of ion solvation. Effective radii of hydrated ions. J. Phys. Chem. 1959, 63, 1381-1387. [CrossRef]

21. Richter, C.; Schmuttenmaer, C.A. Exciton-like trap states limit electron mobility in $\mathrm{TiO}_{2}$ nanotubes. Nat. Nanotechnol. 2010, 5, 769-772. [CrossRef] [PubMed]

22. Li, X.; Close, T.; Pustulka, S.; Pedu, S.; Xue, Y.; Richter, C.; Taboada-Serrano, P. Electrosorption of monovalent alkaline metal ions onto highly ordered mesoporous titanium dioxide nanotube electrodes. Electrochim. Acta 2017, 231, 632-640. [CrossRef]

23. McCrory, C.C.; Jung, S.; Peters, J.C.; Jaramillo, T.F. Benchmarking heterogeneous electrocatalysts for the oxygen evolution reaction. J. Am. Chem. Soc. 2013, 135, 16977-16987. [CrossRef] [PubMed]

24. Benck, J.D.; Chen, Z.; Kuritzky, L.Y.; Forman, A.J.; Jaramillo, T.F. Amorphous molybdenum sulfide catalysts for electrochemical hydrogen production: Insights into the origin of their catalytic activity. ACS Catal. 2012, 2, 1916-1923. [CrossRef]

25. Bockris, J.M.; Srinivasan, S. Electrode kinetic aspects of electrochemical energy conversion. J. Electroanal. Chem. 1966, 11, 350-389. [CrossRef]

26. Boggio, R.; Carugati, A.; Trasatti, S. Electrochemical surface properties of $\mathrm{Co}_{3} \mathrm{O}_{4}$ electrodes. J. Appl. Electrochem. 1987, 17, 828-840. [CrossRef]

27. Orazem, M.E.; Tribollet, B. Electrochemical Impedance Spectroscopy; John Wiley \& Sons, Inc.: Hoboken, NJ, USA, 2008; pp. 233-237.

28. Brug, G.; Van Den Eeden, A.; Sluyters-Rehbach, M.; Sluyters, J. The analysis of electrode impedances complicated by the presence of a constant phase element. J. Electroanal. Chem. Interfacial Electrochem. 1984, 176, 275-295. [CrossRef]

29. Taboada-Serrano, P.; Yiacoumi, S.; Tsouris, C. Behavior of mixtures of symmetric and asymmetric electrolytes near discretely charged planar surfaces: A Monte Carlo study. J. Chem. Phys. 2005, 123, 054703. [CrossRef] [PubMed]

30. Hou, C.-H. Monte Carlo simulation of electrical double-layer formation from mixtures of electrolytes inside nanopores. J. Chem. Phys. 2008, 128, 044705. [CrossRef] [PubMed]

31. Hou, C.-H.; Taboada-Serrano, P.; Yiacoumi, S.; Tsouris, C. Electrosorption selectivity of ions from mixtures of electrolytes inside nanopores. J. Chem. Phys. 2008, 129, 224703. [CrossRef] [PubMed]

32. Ney, E.M.; Hou, C.-H.; Taboada-Serrano, P. Calculation of electrical double layer potential profiles in nanopores from grand canonical Monte Carlo simulations. J. Chem. Eng. Data 2018. [CrossRef]

(C) 2018 by the authors. Licensee MDPI, Basel, Switzerland. This article is an open access article distributed under the terms and conditions of the Creative Commons Attribution (CC BY) license (http://creativecommons.org/licenses/by/4.0/). 